\title{
On the improvement of thermal comfort in indoor spaces conditioned by split-type systems
}

\author{
Silva Júnior Anastácio da ${ }^{1,3 *}$, Cordeiro Mendonça Kátia ${ }^{2}$, Vilain Rogério ${ }^{1}$, Pereira Marcelo Luiz ${ }^{1}$ and Mendes Nathan ${ }^{3}$ \\ ${ }^{1}$ Instituto Federal de Santa Catarina, São José, Brazil \\ ${ }^{2}$ École d'Ingénieurs CESI - LINEACT, Lagord, France \\ ${ }^{3}$ Pontifícia Universidade Católica do Paraná, Curitiba, Brazil
}

\begin{abstract}
Conventional on/off-based control split-type appliances are widely used in classrooms and offices, in Brazil and in many other countries, due to their low cost and ease of installation. However, occupants often complain about thermal discomfort depending on their position within the conditioned space, especially in positions that are directly affected by the draft, since those equipment provide high cold air velocities as a result of their high cooling capacity relatively to their air supply area. In order to improve the indoor thermal comfort in spaces conditioned by this kind of system, a simplified empirical model for controlling both the supply airflow and the temperature set-point is proposed in this work. In view of that, the comfort conditions in an occupied classroom were experimentally evaluated according to ISO 7730 Standard, which defines the thermal satisfaction in occupied environments based on the PMV index. Specifically, the speed, temperature and relative humidity of the air and the mean radiant temperature of the room were measured at 8 positions within the air conditioned space, for the three original air flows (high, medium and low) of a 10.5-kW cooling capacity appliance and three set-point temperatures $\left(23,24\right.$ and $\left.25^{\circ} \mathrm{C}\right)$. The simplified model, correlating thermal comfort and the variables that could be directly controlled by the split-type system (airflow rate and temperature), was obtained by adjusting several curves from 72 measuring assemblies ( 8 measuring points, 3 set-point temperatures and 3 supply airflows). The correlation that best represents the distribution of thermal comfort throughout the conditioned environment was provided by the non-linear regression method of Levenberg-Marquardt.
\end{abstract}

\section{Introduction}

Split-type equipment has been used in a large scale in residential and commercial air conditioning, being currently the most used in these environments [1]. In Brazil, approximately 4 million of "high-wall split" units were sold in 2010, with capacities below 30,000 BTU/h $(10.5 \mathrm{~kW})$, and the perspectives of the manufacturers are to increase sales for the next few years [1]. The numbers show variation in the type of air conditioning equipment sold in Brazil. Window-type units, which accounted for $60 \%$ of sales 10 years ago, currently represent only $15 \%$, in contrast to the $70 \%$ of split-types [2]. The popularization of the use of split-type air conditioning equipment in various types of environments indicates the need to study in detail the impact of this equipment on the thermal comfort for occupants $[3,4,5]$. In the more recent models, it has been shown that the decrease of its size leads to increasingly lower supply air temperatures, resulting in the risk of thermal discomfort in positions directly affected by the cold blowing jet [5].
Therefore, despite its low cost and ease of installation, this type of air conditioning system presents some drawbacks for both, indoor air quality and thermal comfort for the occupants $[6,7,8]$, The energy consumption of buildings depends on the criteria used for the indoor environment, which also affect health, productivity and comfort of the occupants Than the energy-saving should not sacrifice people's comfort and health $[6,7,9]$.

To have a comfortable environment and good health for people in climatized enviroments the thermal comfort is an important factor for designing high-quality buildings $[4,7,9]$. To reach a comfort indoor environment, air conditioning and ventilation systems are installed inside the occupied eviroments [3].

The objective of this work is to contribute to the improvement of thermal comfort in spaces conditioned by split-type systems, by providing a simplified model to control two operating variables of the equipment (temperature and airflow of the supply air) instead of only one variable (supply temperature).

In order to achieve this goal, the thermal comfort conditions, represented by the PMV (Predicted Mean Vote) index [8], were evaluated experimentally at 8

\footnotetext{
* Corresponding author: anastac@ifsc.edu.br
} 
positions within a school environment taking into account 3 set-point temperatures and 3 supply airflows.

A non-linear regression method was then applied to the resulting measurement data in view of determining the correlation that best represents the distribution of thermal comfort throughout the conditioned environment.

\section{METHODOLOGY}

\subsection{Experimental environment}

The experiments were carried out in a standard classroom of a technical school located in Florianópolis, Santa Catarina State, Brazil. As illustrated in Figure 1, the studied room, whose dimensions are $9 \times 6 \times 3 \mathrm{~m}$, contains 30 desktops and a table for the teacher, i.e., 31 people in their maximum occupancy.

The air in the room is conditioned by a split-type device of $36,000 \mathrm{BTU} / \mathrm{h}(10.5 \mathrm{~kW})$ cooling capacity, which can be supplied at three different velocities (high, medium and low). The equipment was installed at the position indicated in Figure 1.

In this study, the air speed $\left(\mathrm{V}_{\mathrm{ar}}\right)$, temperature $\left(\mathrm{T}_{\mathrm{ar}}\right)$, and relative humidity $\left(\mathrm{RH}_{\mathrm{ar}}\right)$ of the air and the mean radiant temperature $\left(T_{g}\right)$ of the room were measured at breathing height, $1.10 \mathrm{~m}$, by sensors distributed within the room according to Figure 2.

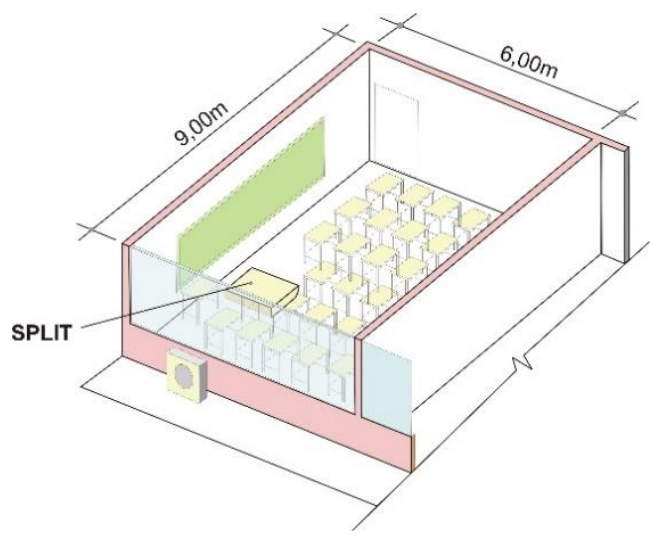

Fig. 1. Studied classroom: Geometry, layout and position of the split-type system tested.

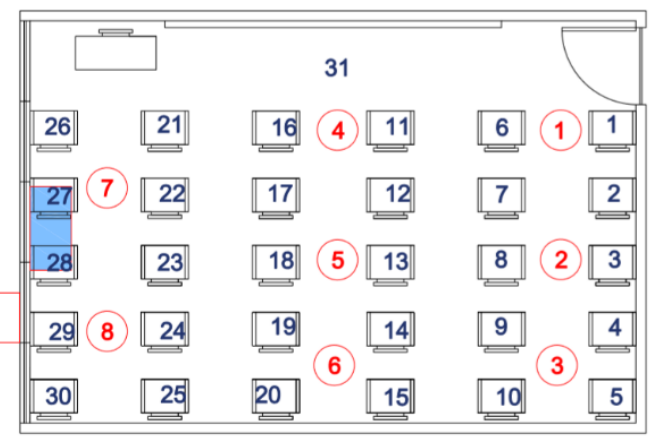

In each of the eight measurement points, the experimental data have been collected for 20 minutes, and recorded at each 30 seconds.

The tests were performed in summer (south hemisphere) with the equipment in cooling mode at three temperature set points $\left(23,24,25^{\circ} \mathrm{C}\right)$ that were measured at the split air return. The room occupancy was equal to 23 people. The studied classroom occupation and the experimental apparatus are showed in Figure 3 a) and b).

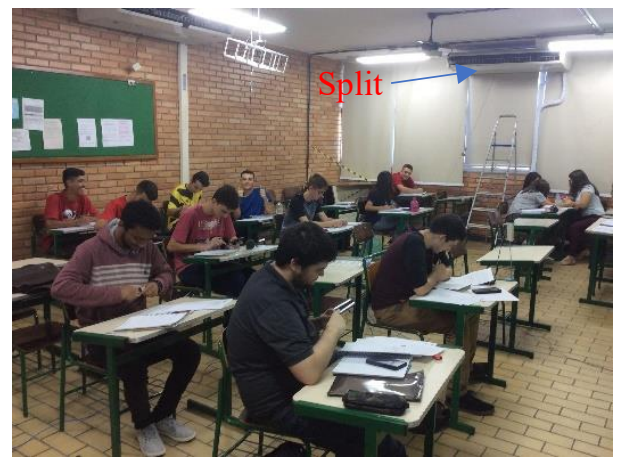

a)

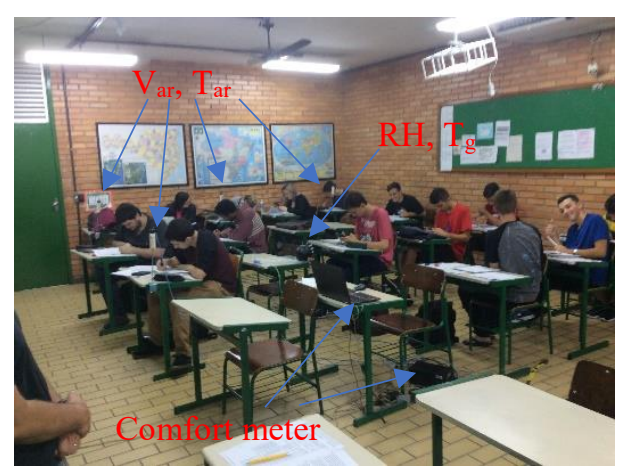

b)

Fig. 3. Studied classroom occupation and experimental apparatus, a) Split, b) Sensors

The comfort conditions in the occupied classroom were evaluated then by calculating the PMV (Predicted Mean Vote) index [8] from the average of 20 readings, in which the independent variables $\mathrm{M}$ and $\mathrm{I}_{\mathrm{cl}}$ were estimated for summer conditions according to $[6,8]$. The metabolic rate $(\mathrm{M})$ is equal to 1.2 met (sedentary activity - school) and the thermal insulation for daily wear clothing $\left(\mathrm{I}_{\mathrm{cl}}\right)$ is equal to 0.50 corresponding to typical student's clothes (underpants, short-sleeve shirts, light trousers, light socks and shoes).

The acceptable values of air velocity at person position for comfort are 0.3 to $0.8[6,8,16]$.

The volumetric airflow rates corresponding to the low $(4.2 \mathrm{~m} / \mathrm{s})$, medium $(4.7 \mathrm{~m} / \mathrm{s})$ and high $(5.2 \mathrm{~m} / \mathrm{s})$ supply air velocities are $0.50,0.56,0.61 \mathrm{~m}^{3} / \mathrm{s}$, respectively, according to the manufacturer's catalogue.

Fig. 2. Studied classroom: Measurement points. 


\subsection{Uncertainty analysis}

The uncertainty of a variable that cannot be measured directly can be estimated from the uncertainties of the variables on which it depends $[6,10]$. In the case of the PMV, dependent on the variables $\mathrm{T}_{\mathrm{ar}}, \mathrm{RH}_{\mathrm{ar}}, \mathrm{T}_{\mathrm{g}}, \mathrm{V}_{\mathrm{ar}}, \mathrm{M}$ and $\mathrm{I}_{\mathrm{cl}}$, its measurement uncertainty (IR) can be expressed by Equation 1.

$I R_{P M V}=\sqrt{\begin{array}{l}\left(\frac{\partial P M V}{\partial T_{a r}} I R_{T_{a r}}\right)^{2}+\left(\frac{\partial P M V}{\partial T_{g}} I R_{T_{g}}\right)^{2}+\left(\frac{\partial P M V}{\partial R H_{a r}} I R_{R H_{a r}}\right)^{2}+ \\ \left(\frac{\partial P M V}{\partial V_{a r}} I R_{V_{a r}}\right)^{2}+\left(\frac{\partial P M V}{\partial M} I R_{M}\right)^{2}+\left(\frac{\partial P M V}{\partial I_{c l}} I R_{I_{c l}}\right)^{2}\end{array}}$

Typical measurements for the tested device at medium supply velocity are showed at Table 1.

Table 1. Typical Measurements for Split A at medium supply velocity.

\begin{tabular}{|c|c|c|c|c|c|}
\hline \multicolumn{4}{|c|}{ Measured } & \multicolumn{2}{c|}{ Assigned } \\
\hline $\begin{array}{c}\mathrm{T}_{\mathrm{ar}} \\
{\left[{ }^{\circ} \mathrm{C}\right]}\end{array}$ & $\begin{array}{c}\mathrm{T}_{\mathrm{g}} \\
{\left[{ }^{\circ} \mathrm{C}\right]}\end{array}$ & $\begin{array}{c}\mathrm{RH}_{\mathrm{ar}} \\
{[\%]}\end{array}$ & $\begin{array}{c}\mathrm{V}_{\mathrm{ar}} \\
{[\mathrm{m} / \mathrm{s}]}\end{array}$ & $\begin{array}{c}\mathrm{M} \\
{[\mathrm{met}]}\end{array}$ & $\begin{array}{c}\mathrm{I}_{\mathrm{cl}} \\
{[\mathrm{Clo}]}\end{array}$ \\
\hline 23.4 & 23.5 & 63 & 0.22 & 1.2 & 0.5 \\
\hline
\end{tabular}

The uncertainties of the measured variables, $T_{a r}$, $\mathrm{RH}_{\mathrm{ar}}, \mathrm{T}_{\mathrm{g}}, \mathrm{V}_{\mathrm{ar}}$, are those indicated in Table 2 corresponding to the uncertainties measurement system [12]. The uncertainties of the variables $\mathrm{M}$ and $\mathrm{I}_{\mathrm{cl}}$ were obtained from the available literature and assume respectively the following values: 0.10 met and 0.16 Clo $[13,14]$.

Table 2. Uncertainties of the measured variables.

\begin{tabular}{|c|c|c|c|c|c|}
\hline \multicolumn{7}{|c|}{ Variables uncertainty } \\
\hline$\frac{\partial P M V}{\partial T_{a r}}$ & $\frac{\partial P M V}{\partial T_{g}}$ & $\frac{\partial P M V}{\partial U R_{a r}}$ & $\frac{\partial P M V}{\partial V_{a r}}$ & $\frac{\partial P M V}{\partial M}$ & $\frac{\partial P M V}{\partial C l o}$ \\
\hline \pm 0.2 & \pm 0.2 & \pm 3 & \pm 0.05 & \pm 0.10 & \pm 0.16 \\
\hline
\end{tabular}

According to Table 3, the parameters whose uncertainties impact the most on the PMV uncertainty are $\mathrm{V}_{\mathrm{ar}}, \mathrm{M}$ and $\mathrm{I}_{\mathrm{cl}}$, while the impact of $\mathrm{T}_{\mathrm{ar}}$ and $\mathrm{T}_{\mathrm{g}}$ uncertainties are similar and moderate and that from $\mathrm{RH}_{\mathrm{ar}}$ is the less pronounced. The results above differ quite a lot from the uncertainty analysis carried out by [15] specially with regards to the influence of the radiant temperature and air temperature, showing that it is important to analyse the uncertainties for PMV assessment.

Table 3. parameters whose uncertainties impact on the PMV uncertainty.

\begin{tabular}{|c|c|c|c|c|c|}
\hline$\frac{\partial P M V}{\partial T_{a r}}$ & $\frac{\partial P M V}{\partial T_{g}}$ & $\frac{\partial P M V}{\partial R H_{a r}}$ & $\frac{\partial P M V}{\partial V_{a r}}$ & $\frac{\partial P M V}{\partial M}$ & $\frac{\partial P M V}{\partial I_{c l}}$ \\
\hline 0.359 & 0.239 & 0.0064 & -2.36 & +2.90 & +2.70 \\
\hline
\end{tabular}

For a typical set of measurements values, as indicated in Table 1, with the uncertainty associated with each variable for the medium flow rate, the result of measurement uncertainty ( $\left(\mathrm{R}_{\mathrm{PMV}}\right)$ is \pm 0.5 , calculated by Equation.

\section{Results and discussion}

The results of PMV distribution in the classroom and the model for a simplified comfort index equation (ICS) will be discussed in the next items.

\subsection{PMV distribution}

The PMV distributions in the horizontal plane at 1.1 $\mathrm{m}$ high from the floor, for the three airflow rates (high, medium and low), are shown in Figures 4, 5 and 6 respectively for the temperature setpoints of 23,24 and $25^{\circ} \mathrm{C}$.

For the setpoint $23^{\circ} \mathrm{C}$, Figure 4 shows that the PMV distribution, for the three airflow rates and values, are similar, all below 0 , and the lowest values $(\approx-1)$ are in the back of the classroom, opposite to the blackboard.

For the setpoint of $24^{\circ} \mathrm{C}$, the PMV values are higher, except for the high airflow, and for the other two airflows, the values are practically the same $(\approx-0.3)$, Figure 5 .

The last case $\left(25^{\circ} \mathrm{C}\right)$, the PMV scale was changed to a better contours visualization. The PMV distribution are almost equal for the three airflows, and near to the neutral thermal comfort sensations $(\approx 0)$, with values above and below zero, i.e., this is the best situation for all the setpoints analyzed, Figure 6.
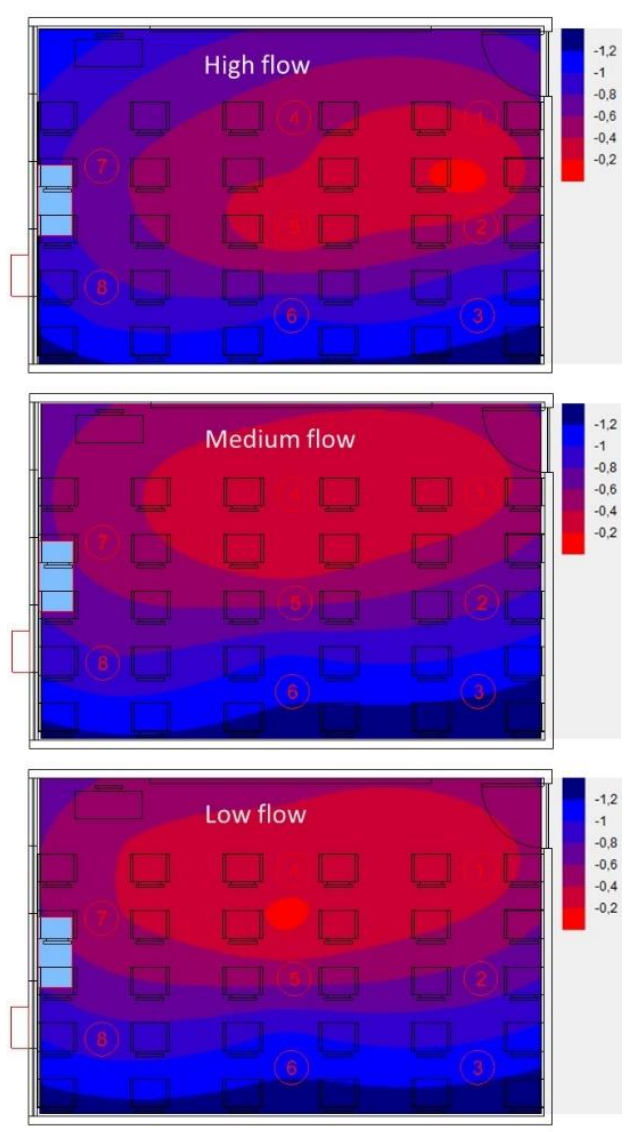

Fig. 4. PMV distributions in the studied classroom, for the three air flow rates and the set point temperature of $23^{\circ} \mathrm{C}$. 

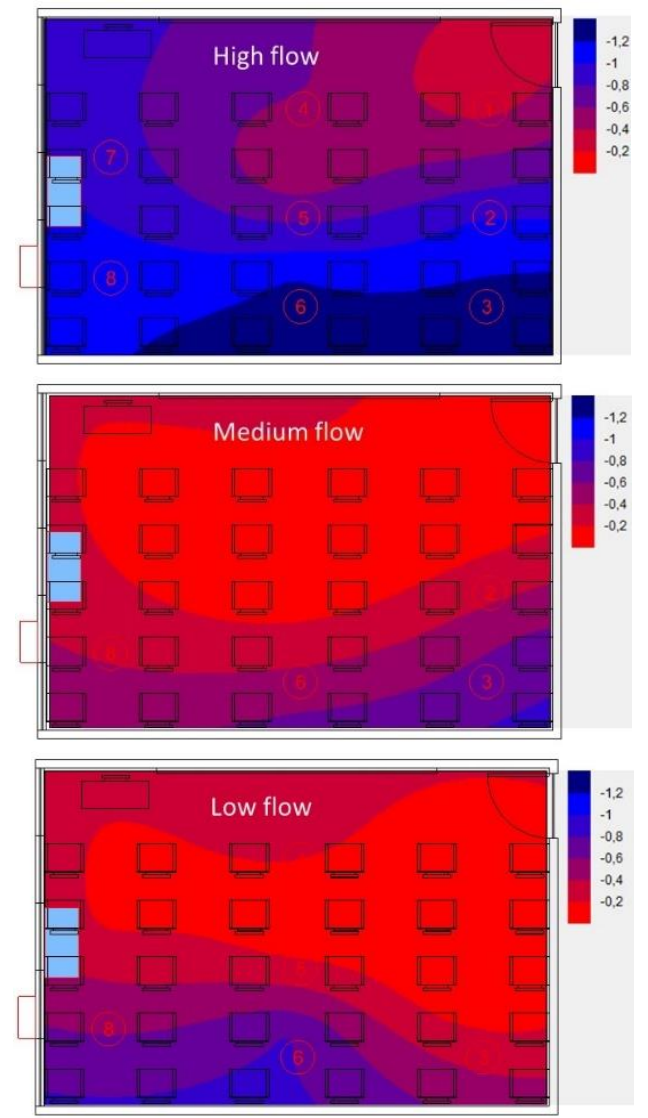

Fig. 5. PMV distribution in the studied classroom, for the three air flow rates and the set-point temperature of $24^{\circ} \mathrm{C}$
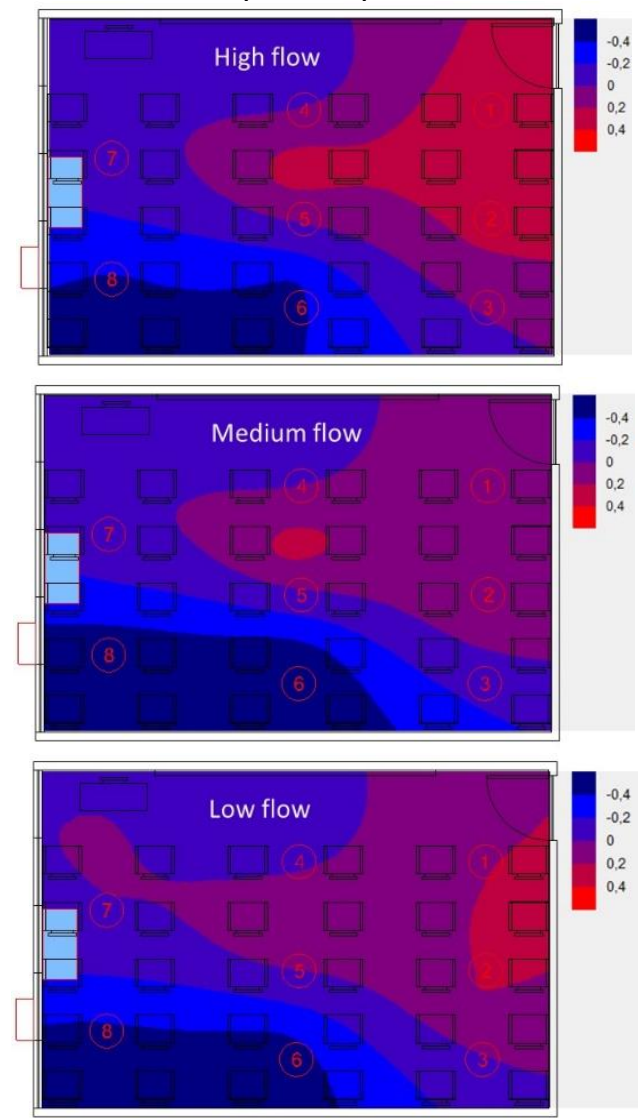

Fig. 6. PMV distribution in the studied classroom, for the three air flow rates and the set-point temperature of $25^{\circ} \mathrm{C}$

\subsection{Correlation between PMV and the parameters $\mathrm{T}_{\mathrm{ar}} \& \mathbf{V}_{\mathrm{ar}}$}

To obtain a simplified model correlating thermal comfort and the variables that could be directly controlled by the split-type system (airflow rate and temperature), several curves were adjusted from the 72 measuring assemblies ( 8 measuring points, 3 temperature set-points and 3 supply airflows) carried out in the classroom.

The curve of PMV as a function of $T_{a r}$ and $V_{a r}$ that best represents the new comfort index distribution within the air-conditioned environment, now called ICS (Comfort index for environment climatized by split-type system) is expressed by the model resulting from the Levenberg-Marquardt's nonlinear regression method [17], expressed by Equation 2:

$$
\begin{gathered}
I C S=a+\frac{b}{V_{a r}}+c * T_{a r}+\frac{d}{V_{a r}{ }^{2}}+e * T_{a r}{ }^{2}+\frac{f * T_{a r}}{V_{a r}}+\frac{g}{V_{a r}{ }^{3}}+ \\
h * T_{a r}{ }^{3}+\frac{i * T_{a r}{ }^{2}}{V_{a r}}+\frac{j * T_{a r}}{V_{a r}{ }^{2}}
\end{gathered}
$$

The Equation 2 for ICS, is valid for the studied range of temperature $\left(23{ }^{\circ} \mathrm{C}\right.$ to $\left.25^{\circ} \mathrm{C}\right)$ and air velocity ( 0 a 0.8 $\mathrm{m} / \mathrm{s}$ ).

The multiple regression coefficient $\left(\mathrm{R}^{2}\right)$, that is the proportion of the variance in the dependent variable that is predictable from the independent variables $\left(\mathrm{T}_{\mathrm{ar}}\right.$ and $\left.\mathrm{V}_{\mathrm{ar}}\right)$ is 0.96 , and it is considered appropriate to the equation of the case studied, i.e., $96 \%$ of the ICS values (dependent variable) can be explained by the regressors present in the model.

\section{Conclusions}

This paper presented an experimental research focused on the improvement of thermal comfort in classrooms conditioned by split-type air conditioners. First, the experimental apparatus was presented, showing un uncertainty analysis for PMV of \pm 0.50 .

Then, the analysis of the PMV for different points within the classroom revealed a neutral thermal environment (PMV near zero) to slightly cool (PMV = 1) with the cold jet a little deflected from the centerline of the room due to the geometry - because the chairs are positioned a little distant from the blackboard, for the three airflow rates and the three set-point temperatures tested.

To conclude, a simplified empirical model obtained by means of a non-linear regression model - LevenbergMarquardt was presented. The ICS index provides the thermal comfort condition when the air temperature and air speed are measured in a point within the room that may enable the control of the split-type equipment setpoint and airflow rate via a PLC (programmable logical controller). This equation was developed for summer conditions and near uniform thermal conditions, i.e., similar values between the air temperature and the mean radiant temperature.

Although the initial idea was to control mainly the airflow rate to avoid the points of discomfort caused by 
the split-type draft, the results of this work showed that controlling the setpoint is more effective to achieve a better thermal comfort environment.

\section{Acknowledgements}

Authors acknowledge CAPES (Coordination for the Improvement of Higher Education Personnel, Brazilian agency) for the grant of doctoral scholarships and financial support for this research.

\section{References}

1. ABRAVA - Associação Brasileira de Refrigeração, Ar Condicionado, Ventilação e Aquecimento Noticias, disponível em http://www.abrava.com.br, acesso em 24/05/2016.

2. Silva, J. G., Wojcikiewicz, G., Garcia, M.A., Instalação De Condicionadores Splits $\mathrm{Na}$ Prática. Kindle Edition - Amazon (2014)

3. Zhang L.Z, NiuIndoor J.L Humidity behaviors associated with decoupled cooling in hot and humid climates. Building and Environment, 38. Pages: 99107 (2003).

4. Thammanoon S., Veerapol M., Sirichai T. Assessment of the thermal environment effects on human comfort and health for the development of novel air conditioning system in tropical regions. Energy and Buildings 42 1692-1702 (2010).

5. Vilain, R., Fabichak Jr., Cálculo De Parâmetros De Conforto Térmico Utilizando Um Manequim Térmico E Uma Sala De Aula Climatizada Com Dois Splits- VII Congresso Nacional de Engenharia Mecânica - CONEM (2012)

6. ISO 7730:2005. Ergonomics of the thermal environment - Analytical determination and interpretation of thermal comfort using calculation of the PMV and PPD indices and local thermal comfort criteria, Geneva, Switzerland: International Organization for Standardization (2005).

7. Bjarne W. O. The philosophy behind EN15251: Indoor environmental criteria for design and calculation of energy performance of buildings. Energy and Buildings 39 740-749 (2007).

8. ASHRAE Standard 55. Thermal Environmental Conditions for Human Occupancy. American Society of Heating Refrigeration and AirConditioning Engineers, Atlanta (2013)

9. Sato M., Fukayo S., Yano E. Adverse environmental health effect of ultra-low relative humidity indoor air Journal of Occupational Health, 45, pp. 133-136 (2003).

10. Holman, J. P. Experimental Methods for Engineers. McGraw-Hill Book Company (1985)

11. ISO/IEC GUM98-3 - Guide to the expression of uncertainty in measurement (2008)
12. ISO $7726: 1998$. Ergonomics of the thermal environment - Instruments for measuring physical quantities, Geneva, Switzerland: International Organization for Standardization (1998)

13. Oliveira, A. R. Avaliação da Incerteza na Determinação dos Índices de Conforto Térmico PMV e PPD. Dissertação em Engenharia Mecânica apresentada à Faculdade de Ciências e Tecnologia da Universidade de Coimbra. Portugal (2008)

14. Trebien, R. Thermal Comfort Sensitivity Analysis and Sensor Development for Control Purposes. The Mechanical Engineering Graduate Program at the Pontifical Catholic University of Paraná. Pontifical Catholic University of Paraná - PUCPR-Curitiba (2008)

15. Alfano, F. R. A.; Palella, B. Igor; Riccio, G. The role of measurement accuracy on the thermal environment assessment by means of PMV index. Building and Environment Volume: 46 Issue: 7 Pages: 1361-1369 (2011).

16. Cândido, C. et al. Aplicabilidade dos limites da velocidade do ar para efeito de conforto térmico em climas quentes e úmidos. Ambiente Construído, Porto Alegre, v. 10, n. 4, p. 59-68, out./dez. 2010

17. Benatti, K. A. O Método de Levenberg-Marquardt para o Problema de Quadrados Mínimos Não Linear. Dissertação de Mestrado em Matemática. UFPR (2017). 